\title{
Postoperative vault hematoma following vaginal hysterectomy: case reports
}

\author{
Amit Gupta $^{1 *}$, Tanu Verma ${ }^{1}$, Bharti Gupta ${ }^{2}$, Anju Vij ${ }^{1}$, Rajinder Kumar ${ }^{1}$
}

\begin{abstract}
${ }^{1}$ Department of Obstetrics and Gynecology, ${ }^{2}$ Department of Anesthesiology, Dr. Rajendra Prasad Government Medical College, Tanda, Kangra, Himachal Pradesh, India
\end{abstract}

Received: 21 June 2018

Accepted: 24 July 2018

\author{
*Correspondence: \\ Dr. Amit Gupta, \\ E-mail: dramit203@yahoo.com
}

Copyright: (C) the author(s), publisher and licensee Medip Academy. This is an open-access article distributed under the terms of the Creative Commons Attribution Non-Commercial License, which permits unrestricted non-commercial use, distribution, and reproduction in any medium, provided the original work is properly cited.

\begin{abstract}
Postoperative vault hematoma is almost a universal consequence of gynaecologic surgery. It usually occurs after vaginal or abdominal hysterectomy. At one end there can be are minimal collection of peritoneal fluid or blood which is clinically insignificant whereas at the other end is the hematoma and abscess requiring active intervention for the patient to recover. We here present two cases of vault hematoma following vaginal hysterectomy which were reported to our institution in recent times. In both cases hematomas were infected. Ultrasonography was used to accurately identify and define the extent of hematomas. The patients underwent vault exploration and drainage. Post-operative period remained uneventful. Postoperative vault hematoma can be diagnosed in the early postoperative period of gynaecologic surgery. It is important to consider the possibility of vault haematoma in patients with persistent fever and vaginal bleeding after hysterectomy. The hematoma cavity can be easily entered to drain hematoma or abscess completely, expediting the recovery of the patient. Refining surgical techniques will significantly reduce the risk of vault hematoma.
\end{abstract}

Keywords: Hematoma, Hysterectomy, Vault

\section{INTRODUCTION}

The most common operation performed in the field of gynaecology is hysterectomy. For some years it has been recognized that vaginal hysterectomy has advantages over abdominal hysterectomy. The incidence of vaginal hysterectomy is rising as it is increasingly done for nonprolapsed uterus. ${ }^{1}$ This route is associated with less febrile morbidity, less risk of hemorrhage, fewer blood transfusions, shorter hospitalization, and quick convalescence as compared to abdominal route. ${ }^{2}$

Even with this procedure, some complications like hemorrhage, postoperative fever, and infection were reported..$^{3-6}$ Collection of blood in the region of vaginal vault after hysterectomy is a common complication. ${ }^{1}$ It leads to increased febrile morbidity, need for blood transfusion, longer hospital stay and higher re-admission rate.

Ultrasound is used routinely nowadays to diagnose the hematoma in the incipient stage without causing discomfort to the patient. Surgeon's experience and skill is an important factor in occurrence of vault haematoma: paying particular attention to potential bleeders during operation is especially important. ${ }^{7}$

Such hematomas can be managed conservatively or require active drainage depending on their size, condition of the patient and infection. 


\section{CASE REPORT}

\section{Case report 1}

A 50 years old woman operated for vaginal hysterectomy for prolapsed uterus, 10 days back at a private clinic referred to Dr. RPGMC Tanda with complaints of bleeding per vaginum from last two days with fever for one day. There were no bowel and bladder complaints. On examination general condition of patient was good with stable vitals with mild fever and on per speculum examination bleeding from vault was present. On ultrasound, there was a collection of $87 \times 78 \times 92 \mathrm{~mm}$ present in pelvis, predominantly liquid with solid elements suggesting hematoma.

\section{Case report 2}

A 46 years old woman operated for vaginal hysterectomy for prolapsed uterus, 11 days back at the same private clinic as case 1 , referred to Dr. RPGMC Tanda with history of fever, pain lower abdomen and retention of urine. On examination patient was febrile with tachycardia and the vault was healthy on per speculum examination whereas there was a firm collection felt in pelvis about $8 \times 6 \mathrm{~cm}$ which was non-tender, non-mobile on per rectal examination. On Ultrasonography, urinary bladder was distended with urine and an extra-peritoneal collection of $82 \times 78 \times 74 \mathrm{~mm}$ in pelvis was present most likely hematoma.

\section{Management}

After baseline investigations in both cases including complete blood count, bleeding time, clotting time, coagulation profile, an ultrasound pelvis was done to confirm the diagnosis and to rule out any intra peritoneal bleeding. In both cases leucocytes were raised, rest all blood investigations including coagulation profile, BT, $\mathrm{CT}$ and platelets were in within normal limits. Both patients were taken for operative procedures after blood arrangement and pre-anaesthetic check-up.

In case 1, examination under anaesthesia was done followed by vault opening and hematoma was drained, approximately 450 - $500 \mathrm{ml}$ of clotted blood drained out. There were no active bleeders found on exploration and a drain was kept and vault was closed. The postoperative course was unremarkable, and drain was removed on $3^{\text {rd }}$ post-operative day. Patient was discharged on day 5 .

In case 2, vault and sutures were grossly healthy, after opening vault about $500 \mathrm{ml}$ of clotted mixed with unclotted blood was drained. no active bleeders were found on exploration. A drain is drain inserted through the drainage tract and left in place for 2 days. Patient remained febrile in initial postoperative period and put on intravenous antibiotics. She recovered and discharged on postoperative day 6 .

\section{DISCUSSION}

Vault hematoma or abscess is a common complication of gynaecologic surgery. Post hysterectomy hematomas are responsible for serous morbidity especially if they are large and infected. ${ }^{8}$ Rarely there can be collection of lymph, serous fluid or necrotic debris at different sites after hysterectomy. Mostly the collection occurred in the dependent areas. Hematomas can be formed in pouch of Douglas, subvesical space, ischio-rectal fossa and broad ligament. ${ }^{1}$

It is difficult to diagnose hematoma by routine clinical examination only. Many patients may be asymptomatic; whereas some may present with postoperative bleeding per vaginum (spotting to profuse bleeding per vaginum), postoperative discomfort, abdominal distension, paralytic ileus, continuous fever, foul smelling discharge per vaginum, abscess formation, tenesmus, nausea, vomiting, and diarrhoea. ${ }^{2}$

Ultrasound, being an accessible, non-invasive and accurate diagnostic tool, seems to be the modality of choice for diagnosing postoperative vault hematoma. ${ }^{3}$ In a study, the overall incidence of vault hematoma was $19.4 \%, 70 \%$ had small-sized hematoma and $30 \%$ had large sized hematoma. ${ }^{2}$

Small vaginal vault hematomas $(2-3.9 \mathrm{~cm})$ unlikely to cause postoperative morbidity and can be managed expectantly. They can be left alone with watchful expectancy and follow-up ultrasonography for resolution of the hematoma done weekly. ${ }^{2}$

Moderate $(4-5.9 \mathrm{~cm})$ and large $(>6 \mathrm{~cm})$ hematomas need further management. An extended morbid and complicated postoperative course can be alleviated if the hematoma can be drained. A small drain may be inserted through the drainage tract and left in place for a day or so. If the hematoma can be drained the patient's recovery will be more prompt. ${ }^{9}$

Refinement in surgical techniques is recommended to minimize the risk of clinically significant vaginal vault haematomas after vaginal hysterectomy. ${ }^{10}$

\section{CONCLUSION}

The incidence of vault hematomas is more following vaginal hysterectomies due to inadequate haemostasis and infection. Postoperative ultrasound is a good diagnostic tool. Small haematomas can be managed conservatively however large infected hematomas need drainage. Refining surgical techniques will significantly reduce the risk of vault hematoma.

Funding: No funding sources

Conflict of interest: None declared

Ethical approval: Not required 


\section{REFERENCES}

1. Chaudhry SM, Anwer S. Presentation and management of vaginal vault hematoma after hysterectomy. J Surg Pakistan. 2016;21(1):35-8.

2. Dane C, Dane B, Cetin A, Yayla M. Sonographically diagnosed vault hematomas following vaginal hysterectomy and its correlation with postoperative morbidity. Infectious diseases in obstetrics and gynecology. 2007;2007.

3. Slimani O, Alaoui F, Jayi S, Chaara H, Bouguern H. Postoperative pelvic hematoma an unusual case after surgical treatment of ectopic pregnancy. J Clin Case Rep. 2014;4(422):2.

4. Kuhn RJ, de Crespigny LC. Vault haematoma after vaginal hysterectomy: an invariable sequel?. Aus NZ J Obstet Gynaecol. 1985;25(1):59-62.

5. Slavotinek J, Berman L, Burch D, Keefe B. The incidence and significance of acute posthysterectomy pelvic collections. Clin Radiol. 1995;50(5):322-6.

6. Rosen DM, Cario GM. Vault haematoma following laparoscopic hysterectomy. Aus NZ J Obstet Gynaecol. 1997;37(2):220-2.
7. Cheung KW, Pun TC. Vaginal hysterectomies in patients without uterine prolapse: ten-year experience. Hong Kong Med J. 2013.

8. Thomson AJ, Sproston AR, Farquharson RG. Ultrasound detection of vault haematoma following vaginal hysterectomy. BJOG: Int J Obstet Gynaecol. 1998;105(2):211-5.

9. Rock JA, Thompson JD, editors. Te Lende's operative gynaecology. $8^{\text {th }}$ edn. Philadephia: Lippincott-Raven; 1996.

10. Morris P, El-Toukhy T, Toozs-Hobson P, MA Hefni E. Refining surgical technique to prevent occurrence of vault haematoma after vaginal hysterectomy. J Obstet Gynaecolgy. 2001;21(4):379-82.

Cite this article as: Gupta A, Verma T, Gupta B, Vij A, Kumar R. Postoperative vault hematoma following vaginal hysterectomy: case reports. Int J Reprod Contracept Obstet Gynecol 2018;7:3884-6. 